\title{
CLÁUSULA MARTENS: UNA OPORTUNIDAD PARA LA PROTECCIÓN DEL AMBIENTE EN LOS CONFLICTOS ARMADOS
}

Manuel Francisco Pardo Ballesteros

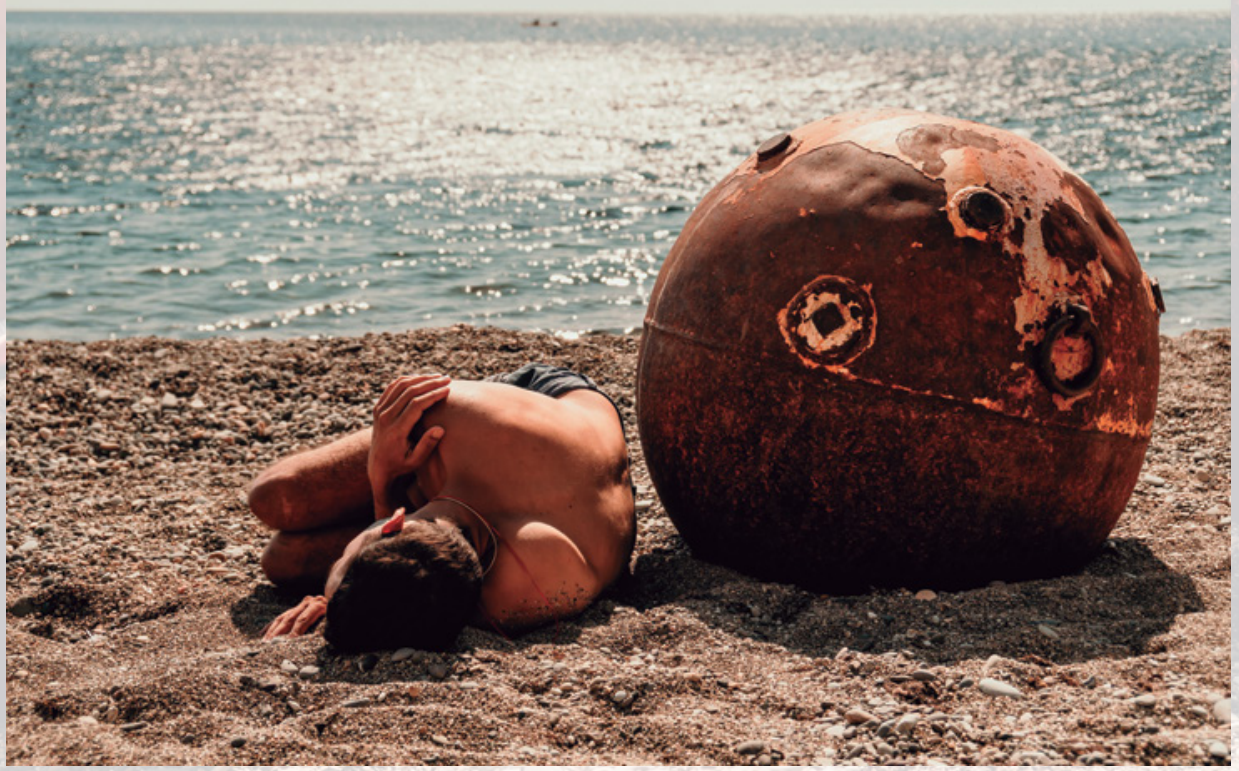





\title{
CLÁUSULA MARTENS: UNA OPORTUNIDAD PARA LA PROTECCIÓN DEL AMBIENTE EN LOS CONFLICTOS ARMADOS
}

\author{
Manuel Francisco Pardo Ballesteros \\ Centro de Estudios en Política \\ y Legislación Ambiental de Colombia
}

\section{Resumen}

Tras el análisis del derecho internacional humanitario (DIH) convencional y consuetudinario, este artículo establece que la insuficiencia de este régimen en la protección del ambiente en los conflictos armados puede ser superado mediante el uso de las exigencias de la conciencia pública de la cláusula Martens y el derecho blando ambiental. Para tal fin, el artículo inicia con el origen, el alcance y las interpretaciones de dicha cláusula y la forma en que esta se erige como una fuente de derecho internacional independiente de las del artículo 38 del Estatuto de la Corte Internacional de Justicia. Acto seguido, se revisan los instrumentos del DIH y la suficiencia para proteger el ambiente. Por último, expone que con la cláusula Martens y las exigencias de la conciencia pública se podría exigir el cumplimiento de las disposiciones del derecho blando ambiental para guiar las conductas de las partes en conflicto.

Palabras clave: derecho internacional humanitario, derecho internacional ambiental, cláusula Martens, derecho blando, protección ambiental, conflictos armados.

El autor: magíster en Derecho Ambiental y Sostenibilidad, abogado, Centro de Estudios en Política y Legislación Ambiental de Colombia (Ceplac). ORCID: 0000-0003-0507-6082. Correo electrónico: pardo.manuel@hotmail.com

Recibido: 31 de octubre de 2021; evaluado: 10 de noviembre de 2021; aceptado: 25 de noviembre de 2021. 


\title{
THE MARTENS CLAUSE: AN OPPORTUNITY TO PROTECT THE ENVIRONMENT IN ARMED CONFLICTS
}

\author{
Manuel Francisco Pardo Ballesteros \\ Centro de Estudios en Política \\ y Legislación Ambiental de Colombia
}

\begin{abstract}
Through the analysis of conventional and customary International Humanitarian Law (IHL), this article shows how its inability to protect the environment in armed conflicts can be overcome by applying the requirements of public conscience included in the Martens Clause and environmental soft law. To this end, the article begins by examining the origin, scope, and interpretations of the Martens Clause and the way in which it stands as a source of international law independent of those of Article 38 of the Statute of the International Court of Justice. IHL instruments and their adequacy in protecting the environment are subsequently analyzed. The paper concludes that the Martens Clause and especially the requirements of public conscience could be used to enforce compliance with the provisions of environmental soft law to guide the conduct of the parties in conflict.
\end{abstract}

Keywords: international humanitarian law, international environmental law, Martens Clause, soft law, environmental protection, armed conflicts.

The author: MA in Environmental Law and Sustainability, lawyer, Centro de Estudios en Política y Legislación Ambiental de Colombia (CEPLAC). ORCID: 0000-0003-0507-6082. E-mail: pardo. manuel@hotmail.com

Received: October 31, 2021; evaluated: November 10, 2021; accepted: November 25, 2021. 


\title{
CLÁUSULA MARTENS: UMA OPORTUNIDADE PARA PROTEGER O AMBIENTE NO CONTEXTO DOS CONFLITOS ARMADOS
}

\author{
Manuel Francisco Pardo Ballesteros \\ Centro de Estudios en Política \\ y Legislación Ambiental de Colombia
}

\section{Resumo}

Após a análise do direito internacional humanitário convencional e consuetudinário, este artigo estabelece que a insuficiência desse regime na proteção do ambiente no contexto dos conflitos armados pode ser superada mediante o uso das exigências da consciência pública da cláusula Martens e o direito suave (soft law) ambiental. Para isso, o artigo inicia com a origem, o escopo e as interpretações dessa cláusula e a forma em que ela é estabelecida como uma fonte de direito internacional independente das do artigo 38 do Estatuto da Corte Internacional de Justiça. Em seguida, foram revisados os instrumentos do direito internacional humanitário e a suficiência para proteger o ambiente. Por último, é exposto que, com a cláusula Martens e as exigências da conscientização pública, poderia ser exigido o cumprimento das disposições do direito suave ambiental para guiar as condutas das partes em conflito.

Palavras-chave: direito internacional humanitário, direito internacional ambiental, cláusula Martens, direito suave, proteção ambiental, conflitos armados.

O autor: mestre em Direito Ambiental e Sustentabilidade, advogado, Centro de Estudos em Política e Legislação Ambiental da Colômbia (Ceplac). ORCID: 0000-0003-0507-6082. Correio eletrônico: pardo.manuel@hotmail.com

Recebido: 31 de outubro de 2021; avaliado: 10 de novembro de 2021; aceito: 25 de novembro de 2021. 


\section{Introducción}

En julio de 2019, un grupo de veintidós científicos de todo el mundo publicó una carta dirigida a la comunidad internacional, con el fin de exhortar a los Estados para que se adoptara una Quinta Convención de Ginebra, ${ }^{1}$ cuyo tema central sería la protección del ambiente en el marco de los conflictos armados.

Un mes después, la Comisión de Derecho Internacional (en adelante, CDI) presentó su informe final sobre la protección del ambiente en relación con los conflictos armados. Uno de los principios propuestos por la CDI hizo referencia a la consagración de la cláusula Martens como su eje, para la protección del ambiente, bien sea ante confrontaciones de carácter internacional o no internacional. Sin embargo, ¿qué implicaría que la cláusula Martens sea usada en estos asuntos?

Para responder lo anterior, en este documento se examinará qué es la cláusula Martens, sus orígenes, interpretaciones y su consagración en los principios de la CDI. Después, se describirá el marco normativo vigente para la protección de ambiente en el DIH y las limitaciones que las disposiciones convencionales y consuetudinarias tienen para este fin. Por último, se explicará que la cláusula Martens es una herramienta que permite incluir los principios de derecho internacional ambiental (en adelante, DIA) y normas del derecho blando ambiental en la protección del ambiente durante los conflictos armados.

\section{Cláusula Martens: contenido, alcance y antecedentes}

Mientras que se forma un Código más completo de las leyes de la guerra, las Altas Partes Contratantes juzgan oportuno declarar que, en los casos no comprendidos en las disposiciones reglamentarias adoptadas por ellas, las poblaciones y los beligerantes permanecen bajo la garantía y el régimen de los principios del Derecho de Gentes preconizados por los usos establecidos entre las naciones civilizadas, por las leyes de la humanidad y por las exigencias de la conciencia pública. ${ }^{2}$

Sarah Durant y José Carlos Brito, "Protect Environment from Armed Conflicts", Nature 571, núm. 7766 (2019): 478

2 Comité Internacional de la Cruz Roja [CICR], Convención relativa a las leyes y costumbres de la guerra terrestre (La Haya, 18 de octubre de 1907), considerando 8. 
Con estas palabras, incluidas en la Convención relativa a las leyes y costumbres de la guerra terrestre de 1899 por el diplomático ruso Friedrich Fromhold Martens, se inmortalizó lo que se conoce como la cláusula Martens. Pustogarov ha rastreado su origen hasta antes de la firma de tal Convención. En la Conferencia de Bruselas, de 1874, el entonces desconocido Friedrich Martens propuso un proyecto de tratado que recogía los principios de la Convención de San Petersburgo, de 1868, y otras costumbres generalizadas para el momento. Dicho tratado vio la luz como la Declaración de Bruselas. ${ }^{3}$ Después, en la primera Conferencia de la Paz, realizada en La Haya, el mismo Martens presentó la Declaración de Bruselas como punto de partida para la negociación de una convención sobre la forma de conducir la guerra, texto que fue adoptado en su integridad, incluida la cláusula citada. ${ }^{4}$

La interpretación sobre su alcance tiene tres grandes vertientes. En primer lugar, la postura estricta de los Estados con gran poder en la comunidad internacional entiende que la cláusula Martens se trata de un párrafo que, tal como indica Sparrow, es de poca monta o redundante. ${ }^{5}$ Se argumenta esto porque se entiende que se asimila a la costumbre internacional, que es vinculante para los Estados, en virtud del artículo 38 del Estatuto de la Corte Internacional de Justicia (en adelante, CIJ).

Desde una postura moderada, la cláusula sirve para la interpretación de los tratados existentes, mas no contiene prohibiciones específicas. Por último, la interpretación más amplia, postura laxa, encuentra que incluye fuentes independientes de derecho. Bajo esta última interpretación, el diseño de la cláusula muestra una clara intención de incluir tres fuentes de derecho internacional, en particular del DIH: i) los usos establecidos entre las naciones civilizadas; ii) las leyes de la humanidad, y iii) las exigencias de la conciencia pública.

¿Podría la cláusula Martens incluir tres fuentes de derecho independientes de las contenidas en el artículo 38 del Estatuto de la CIJ? Desde la tercera tendencia explicada, sí sería posible y se cimenta en el entendimiento general que se ha hecho del derecho internacional público (en adelante, DIP), asunto que se explicará brevemente a continuación.

Vladimir Pustogarov, "The Martens Clause in International Law", Journal of the History of International Law 1, núm. 2 (enero 1999): 125, DOI: https://doi.org/10.1163/15718059920956715 (acceso octubre 12, 2021). Pustogarov, "The Martens Clause", 126-127.

5 Rob Sparrow, "Ethics as a Source of Law: The Martens Clause and Autonomous Weapons", https://blogs.icrc. org/law-and-policy/2017/11/14/ethics-source-law-martens-clause-autonomous-weapons/ (acceso octubre 12, 2021). 
La noción de DIP contemporáneo se ha moldeado con el tiempo, al considerar retos que en el derecho interno no se presentaban, como lo es la ausencia de un Legislador concentrado. ${ }^{6}$ Para definir el DIP se recurrirá a lo expresado por el profesor Valerio de Oliveira Mazzuoli:

En una definición más global (y más técnica), el Derecho Internacional Público puede ser definido como el conjunto de principios y reglas jurídicas (consuetudinarias y convencionales) que disciplinan y rigen la actuación y la conducta de la sociedad internacional (formada por los Estados, por las organizaciones internacionales intergubernamentales y también por las personas), buscando alcanzar las metas comunes de la humanidad y, en último análisis, la paz, la seguridad y estabilidad en las relaciones internacionales. ${ }^{7}$

Cabe preguntarse: ¿de dónde surgen las fuentes de derecho internacional público? Tradicionalmente, se derivan del estudio del artículo 38 del Estatuto de la CIJ y son los tratados, la costumbre internacional y los principios generales de derecho reconocido por las naciones civilizadas; de manera auxiliar, la jurisprudencia y la doctrina se convierten en fuentes de derecho. ${ }^{8}$ Se resalta que el autor considera que este listado no es exhaustivo respecto a las fuentes del DIP; por el contrario, es una hoja de ruta para la Corte en la aplicación del DIP en los casos de su jurisdicción. ${ }^{9}$

A continuación, el autor elabora un listado de fuentes que han sido recogidas por la doctrina y, en algunos casos, por la jurisprudencia. Entre ellas se encuentran los actos unilaterales de los Estados, los actos unilaterales transnacionales y las obligaciones erga omnes, jus cogens y soft law. ${ }^{10}$

Así, la posibilidad de incluir nuevas fuentes de derecho internacional diferentes a las tradicionales es posible. En el caso en concreto, la Convención relativa a las

Fabián Augusto Cárdenas Castañeda, "A Call for Rethinking the Sources of International Law: Soft Law and the Other Side of the Coin", Anuario mexicano de derecho internacional 13 (2013): 356, http://www.scielo.org. $\mathrm{mx} /$ scielo.php?script=sci_abstract\&pid=S1870-46542013000100008\&lng=es\&nrm=iso\&tlng=en (acceso octubre 12, 2021); Víctor Saco, "Resolución de conflictos normativos en derecho internacional público", Agenda Internacional 15, núm. 26 (2008): 232, https://revistas.pucp.edu.pe/index.php/agendainternacional/ article/view/3689 (acceso octubre 12, 2021).

7 Valerio de Oliveira Mazzuoli, Derecho internacional público contemporáneo (Barcelona: Bosch, 2019), 58.

8 Marco Gerardo Monroy-Cabra, "Aproximación al concepto de fuentes del derecho internacional", Estudios Socio-Jurídicos 7, núm. 2 (2005): 83, https://revistas.urosario.edu.co/index.php/sociojuridicos/article/view/166 (acceso octubre 12, 2021).

9 De Oliveira Mazzuoli, Derecho, 109.

10 De Oliveira Mazzuoli, Derecho, 141-169. 
leyes y costumbres de la guerra terrestre es suficiente para que las exigencias de la conciencia pública mencionadas en la cláusula Martens sean consideradas como una fuente de derecho autónoma por su similitud con el Estatuto de la CIJ. Si bien existe cierta coincidencia entre las dos fuentes iniciales de la cláusula Martens y las fuentes tradicionales, la tercera fuente — las exigencias de la conciencia pública— no tiene un término similar en el artículo 38 del Estatuto de la CIJ.

¿Qué son las exigencias de la conciencia pública? Este concepto no es fácil de establecer y muchos suelen confundirlo con los principios generales de derecho, que son parte de las fuentes formales de DIP. Sin embargo, las exigencias de la conciencia pública suponen la integración de muchos más actores y el abandono de esa visión estatal tradicional, para mostrar que se trata de una conciencia generalizada en la sociedad.

El verdadero problema, a juicio de quien escribe, recae en la siguiente pregunta: ¿Cómo se expresan las exigencias de la conciencia pública como fuente de derecho? El magistrado Shahabuddeen de la CIJ intentó responderla y manifestó que, para convalidar la exigencia o conciencia pública, es posible flexibilizar su prueba y entender que son manifestaciones generales de la comunidad internacional. ${ }^{11}$ Documentos como las resoluciones de la Asamblea General de las Naciones Unidas constituyen una muestra clara de esa conciencia pública; de igual forma, el magistrado admite que es posible tener otros medios de prueba idóneos para conocer la conciencia pública. ${ }^{12}$

Desde la academia, Sparrow menciona tres métodos para que esta conciencia pública pueda ser determinada. En primer lugar, mediante las encuestas al público (Estados, organizaciones internacionales, ONG y sociedad civil). Empero, el autor reconoce las limitaciones de la metodología para la obtención de una muestra significativa, ya que garantizar el acceso a todos los lugares del mundo presenta alta complejidad y no acceder a una mayoría de visiones podría reflejar una visión sesgada. ${ }^{13}$

En segundo lugar propone la opinión de expertos, cuyo riesgo radica en la confiabilidad de su imparcialidad. Aunado a lo anterior, esta fórmula se parecería

11 Organización de las Naciones Unidas [ONU], Corte Internacional de Justicia, Opinión consultiva de la Corte Internacional de Justicia sobre la legalidad de la amenaza o el empleo de armas nucleares (Nueva York, 8 de julio de 1996), 188.

12 ONU, Corte Internacional de Justicia, Opinión consultiva de la Corte Internacional de Justicia sobre la legalidad de la amenaza o el empleo de armas nucleares, 180-181.

13 Sparrow, "Ethics". 
mucho a una fuente auxiliar reconocida, como es la doctrina, de tal forma que no se estaría hablando de una fuente independiente. ${ }^{14}$

Por último, Sparrow incluye la deliberación pública, basada en las teorías de la democracia deliberativa y sostiene que un foro donde se reúna la mayor cantidad de visiones con el fin de deliberar y llegar a un acuerdo común denotaría la conciencia pública existente. ${ }^{15}$

Con este panorama, los foros virtuales o presenciales, que reúnen un alto número de visiones, posturas y sujetos podrían llevar a determinar cuál es la exigencia de la conciencia pública. A manera de ejemplo, una conferencia en la que participan Estados, ONG y representantes de las comunidades cuyo resultado es una declaración conjunta podría mostrar estas exigencias y constituir una fuente de derecho autónoma. Para el caso del DIA, los instrumentos del soft law que se entendían no vinculantes podrían serlo en función de esta fuente de derecho.

Desde este entendido, las exigencias de la conciencia pública se erigen como una herramienta adecuada para la protección del ambiente en los conflictos armados. Ante la ausencia de normas específicas que prohíban o limiten un mecanismo de guerra, la conciencia pública podrá ayudar a identificar la pertinencia y legitimidad de dicha práctica. Esta noción se encuentra reforzada en la postura del magistrado Shahabuddeen, quien analiza el alcance de la cláusula Martens y concluye que esta posee una autoridad propia que exige a los Estados una conducta. ${ }^{16}$

El magistrado Shahabuddeen afirmó que, bajo la cláusula Martens, el juez no debe concentrarse únicamente en la existencia de una opinio juris siempre que "las opiniones de los Estados serán pertinentes sólo en la medida que revelen el estado de la conciencia pública [...]".17

El primer antecedente que incluyó esta cláusula para la protección del ambiente en los conflictos armados es el Congreso Mundial de la Naturaleza, realizado en la ciudad de Amán, Jordania, en el año 2000. Si bien no se tienen mayores luces sobre la discusión, mediante la Recomendación 2.97, adoptada por consenso, se

\footnotetext{
Sparrow, "Ethics".

Sparrow, "Ethics".

ONU, Corte Internacional de Justicia, Opinión consultiva de la Corte Internacional de Justicia sobre la legalidad de la amenaza o el empleo de armas nucleares, 179.

17 ONU, Corte Internacional de Justicia, Opinión consultiva de la Corte Internacional de Justicia sobre la legalidad de la amenaza o el empleo de armas nucleares, 179.
} 
consideró la inclusión de esta como eje del cuidado ambiental. Asistieron cerca de 140 delegaciones de diversos países y frente a esta recomendación tan solo Estados Unidos se abstuvo de votar a favor o en contra; los demás Estados votaron favorablemente. De igual manera, acudieron más de 2000 participantes de actores variados como ONG nacionales e internacionales y representantes de comunidades étnicas; ${ }^{18}$ bajo una lupa de representatividad, este es un efectivo validador de la conciencia pública.

En segundo lugar, en el año 2013, la CDI inició el estudio de la protección del ambiente en relación con los conflictos armados. Si bien desde un principio se pretendió examinar la cláusula Martens, no fue sino hasta el segundo informe de Marja Lehto que se profundizó en el tema. En particular, el informe analiza las normas convencionales y consuetudinarias del DIH y decisiones del Tribunal de Núremberg y la CIJ, en las cuales se observa el reconocimiento de dicha cláusula.

Respecto a sus consecuencias jurídicas, el documento afirma que hay divergencia de opiniones. Las posturas de la relatora especial coinciden con las ya expuestas.

Frente a los dictados o las exigencias de la conciencia pública, el informe asimila este término a la expresión "atrocidades que [...] conmueven profundamente la conciencia de la humanidad" usado en el Preámbulo del Estatuto de Roma. Su relación, indica la relatora, radica en que "ninguno de los dos conceptos tiene una clara relación con las fuentes del derecho internacional establecidas. Además, ambos se refieren a nociones más amplias como 'opinión pública' y 'opinión mundial', lo que se ha considerado problemático". ${ }^{19}$

El informe de la relatora especial sostiene que existe la necesidad de ampliar lo que se entiende por conciencia pública, de forma que no debe reducirse a la opinión pública predominante; este concepto debe ceñirse a lo dispuesto en resoluciones y otros actos autorizados de los organismos internacionales representativos. ${ }^{20}$

18 Unión Internacional para la Conservación de la Naturaleza [UICN], "Miembros de la UICN", https://www. iucn.org/es/miembros-de-la-uicn (acceso julio 13, 2021).

19 Organización de las Naciones Unidas [ONU], Comisión de Derecho Internacional, "Segundo informe sobre la protección del medio ambiente en relación con los conflictos armados presentado por Marja Lehto, relatora especial, Doc. A/CN.4/728", https://digitallibrary.un.org/record/3801185/files/A_CN-4_728-ES.pdf (acceso octubre 12, 2021).

20 ONU, Comisión de Derecho Internacional, "Segundo informe", 90. 
En cuanto a las posiciones que apoyan que la cláusula Martens no podría ser usada para la protección del ambiente porque solo abarca a los seres humanos, la relatora plantea que no existe evidencia de que la cláusula tenga dicha limitación; por el contrario, afirma que muestra un claro vínculo entre el ambiente y la humanidad y que, en la actualidad, la tendencia no apunta a discriminarlos, porque es necesario entender que la humanidad se interrelaciona con los componentes del ambiente. ${ }^{21}$

Se concluye que el uso de la cláusula Martens procede cuando el derecho convencional es insuficiente o inexistente, lo que conduce a desarrollar el carácter evolutivo de las situaciones ambientales en el marco de los conflictos armados porque, en la medida en que ha pasado el tiempo, se han podido estudiar de mejor manera los efectos de los conflictos en el ambiente. Así, con la cláusula Martens es posible emplear normas y principios pertinentes del derecho internacional de los derechos humanos y del DIA para interpretar el derecho internacional humanitario. ${ }^{22}$

Revisado el informe, la CDI evaluó y aprobó veintiocho principios que fueron sugeridos por la Relatoría, entre ellos:

Principio 12. Cláusula de Martens con respecto a la protección del medio ambiente en relación con los conflictos armados. En los casos no contemplados por acuerdos internacionales, el medio ambiente quedará bajo la protección y el gobierno de los principios del derecho internacional derivados de la costumbre establecida, los principios de humanidad y de los dictados de la conciencia pública. ${ }^{23}$

Con estos antecedentes cabe preguntar ¿por qué es necesario acudir a la cláusula Martens para proteger el ambiente en los conflictos armados? Como ya se indicó, desde la perspectiva de la recomendación de la CDI, su uso procede cuando el derecho convencional es inexistente o insuficiente. Por tal motivo, a continuación se ofrece una revisión descriptiva del DIH convencional y consuetudinario respecto a su alcance.

ONU, Comisión de Derecho Internacional, "Segundo informe", 91

ONU, Comisión de Derecho Internacional, "Segundo informe", 91.

23 Organización de las Naciones Unidas [ONU], Comisión de Derecho Internacional, "Capítulo VI. Protección del medio ambiente en relación con los conflictos armados, Doc. A/74/10", https://legal.un.org/ilc/reports/2019/ spanish/chp6.pdf (acceso octubre 12, 2021). 


\section{Revisión del derecho internacional humanitario}

Desde la segunda mitad del siglo XX, la preocupación por regular los conflictos se convirtió en un eje de la política internacional. La inquietud por identificar cuándo una confrontación era ecuánime ocupó la mente de diversos estudiosos. Desde la guerra justa de san Agustín de Hipona y la yihad islámica hasta la noción de proscripción de la guerra, tras la Segunda Guerra Mundial, Alberto José Ferrari Puerta nos muestra la evolución de este concepto. ${ }^{24}$

La proscripción jurídica de la agresión como elemento esencial de la soberanía de un Estado fue el inicio de un nuevo paradigma, cuyo núcleo es la solución pacífica de los conflictos entre estos. A pesar de ello, nuevas confrontaciones armadas surgieron en el mundo, lo que causó que la comunidad internacional entendiera la necesidad de regular la forma como las partes afrontaban esa guerra para no repetir las atrocidades vistas en el pasado.

Si bien algunos autores han opinado que se le ha dado poca atención a la protección del ambiente durante los conflictos armados, ya que la esencia del derecho internacional es la atención de las víctimas, ${ }^{25}$ la cantidad de bibliografía que se encuentra al respecto y la propia inclusión de este tema en el trabajo de la CDI demuestra que sí se ha hecho un trabajo considerable. Schmitt ha mostrado que la protección del ambiente en los conflictos armados no es algo nuevo y menciona que, desde la Antigua Grecia, se tenían nociones de los efectos devastadores de la guerra en el entorno. Asimismo, indica que la protección del ambiente siempre ha tenido una regulación en los conflictos, así sea sumaria. ${ }^{26}$

Ya en la revisión del DIH, Gasser considera que la mayor preocupación en la regulación de la guerra giró en torno a fijar límites a las acciones que podían causar un sufrimiento innecesario a las personas y la destrucción de objetos específicos, pero

24 Alberto José Ferrari Puerta, "El concepto de guerra justa a través de los tiempos", Novum Jus 15, núm. 1 (enero-junio, 2021): 91-115, https://novumjus.ucatolica.edu.co/article/view/3485 (acceso octubre 12, 2021).

25 Erik Koppe, "The Principle of Ambituity and the Prohibition against Excessive Collateral Damage to the Environment during Armed Conflict", Nordic Journal of International Law 82, núm. 1 (2013): 54, DOI: https://doi.org/10.1163/15718107-08201004 (acceso octubre 12, 2021).

26 Michael Schmitt, "Humanitarian Law and the Environment", Denver Journal of International Law and Policy 28, núm. 3 (1999): 266-268, https://digitalcommons.du.edu/cgi/viewcontent.cgi?article=1518\&context=djilp (acceso octubre 12, 2021). 
no consideraban el ambiente como un valor completo. Esta situación perduró hasta 1977, cuando un instrumento de DIH incluyó la noción de "ambiente natural" ${ }^{27}$

Gran parte de la academia suele decantarse por entender que el DIH no debe analizarse con otros regímenes. El islam, por ejemplo, considera que el único régimen que puede regular las situaciones de conflicto armado es el DIH y se requiere la adopción de una nueva convención o instrumento de ese régimen que proteja directamente el ambiente. ${ }^{28}$ Una posición similar se puede observar en la carta de los científicos mencionada al inicio de este artículo.

En contraposición, unas teorías han optado por afirmar que la fragmentación del derecho internacional no es adecuada y proponen armonizar el DIH con otros regímenes internacionales como el DIA mediante la analogía ${ }^{29} \mathrm{o}$ el reconocimiento de bienes jurídicos globales como entidades de especial protección en el derecho internacional. ${ }^{30}$ Esta última noción merece ser resaltada, ya que se acerca bastante a la forma de protección recogida en la cláusula Martens respecto a las exigencias de la conciencia pública. Con este entendido, merecen protección unos valores que la comunidad internacional reconoce como valiosos, lo que permite la interpretación de normas de DIH por medio del DIA.

La academia también ha visto en el soft law o derecho blando una herramienta útil para la protección del ambiente en el marco de conflicto armado. El problema de estas normas es que no tienen una fuerza vinculante por sí mismos, de modo que actúan mediante la persuasión y no por la coerción. Así, desde una óptica realista, la falta o ausencia de una corte que emplee estos instrumentos demuestra que estos son irrelevantes. ${ }^{31}$ Por supuesto, desde la propuesta de este documento, el derecho blando resulta un mecanismo útil y vinculante, siempre que exprese la exigencia de la conciencia pública.

27 Hans-Peter Gasser, "For Better Protection of the Natural Environment in Armed Conflict: A Proposal for Action", American Journal of International Law 89, núm. 3 (1995): 638, DOI:10.2307/2204184 (acceso octubre 12, 2021).

28 Jahidul Islam, "The Protection of Environment during Armed Conflict: A Review of IHL", Society \& Change 11, núm. 3 (julio-septiembre, 2017): 63, https://societyandchange.com/uploads/1531545952.pdf (acceso octubre 12, 2021).

29 Silja Vöneky, "A New Shield for the Environment: Peacetime Treaties as Legal Restraints of Wartime Damage", Reciel 9, núm. 1 (2000): 32, https://www.readcube.com/articles/10.1111\%2F1467-9388.00229 (acceso octubre 12, 2021).

30 Vöneky, "A New Shield”, 27-28.

31 Arif Ahmed y Jahid Mustofa, "Role of Soft Law in Environmental Protection: An Overview", Global Journal of Politics and Law Research 4, núm. 2 (marzo 2016): 14, https://www.eajournals.org/wp-content/uploads/ Role-of-Soft-Law-in-Environmental-Protection-An-Overview.pdf (acceso octubre 12, 2021). 


\subsection{Derecho internacional humanitario convencional}

De acuerdo con el Comité Internacional de la Cruz Roja (CICR), el DIH convencional está conformado por 76 tratados, ${ }^{32}$ algunos de los cuales suelen ser clasificados en otros regímenes del derecho internacional, como el derecho penal internacional. A pesar de ello, para este estudio se analiza el listado completo del CICR, en tanto ha desempeñado el rol de "guardián" del DIH. ${ }^{33}$

En esta lista se encuentran diez tratados con alguna referencia directa al ambiente. Así, tan solo el 13,16 \% de los tratados del DIH convencional tienen alguna mención o noción de protección a este o a los recursos naturales. Estos instrumentos son los siguientes:

- Convención II de La Haya de 1899, relativa a las leyes y usos de la guerra terrestre y reglamento anexo.

- Convención relativa a las leyes y costumbres de la guerra terrestre (H.IV), de 1907.

- Convención sobre la prohibición del desarrollo, de la producción y del almacenamiento de armas bacteriológicas (biológicas y toxínicas y sobre su destrucción), de 1972.

- Convención sobre la prohibición de utilizar técnicas de modificación ambiental con fines militares u otros fines hostiles (Enmod), de 1976.

- Protocolo I adicional a los Convenios de Ginebra de 1949, relativo a la protección de las víctimas de los conflictos armados internacionales, de 1977.

- Protocolo sobre prohibiciones o restricciones del empleo de armas incendiarias (Protocolo III) (CCW.P.III), de 1980.

- Convención sobre la prohibición del desarrollo, de la producción, del almacenamiento y del empleo de armas químicas y sobre su destrucción, de 1993.

32 CICR, "Listado de tratados del derecho internacional humanitario", https://ihl-databases.icrc.org/applic/ihl/ ihl.nsf/vwTreatiesByDate.xsp (acceso octubre 5, 2020).

33 Yves Sandoz, "El comité internacional de la Cruz Roja: guardián del derecho internacional humanitario", https://www.icrc.org/es/doc/resources/documents/misc/about-the-icrc-311298.htm (acceso octubre 5, 2020). 
- Manual de San Remo sobre conflictos armados en el mar, de 1994.

- Convención sobre la prohibición del empleo, almacenamiento, producción y transferencia de minas antipersonal y sobre su destrucción, de 1997.

- Estatuto de la Corte Penal Internacional de 1998 y las enmiendas al artículo 8 de 2010 y a los artículos 8bis, 15bis y 15ter, de 2010.

Bárbara Díaz Santis menciona que existen dos tipos de normas que incorporan de manera indirecta la protección del ambiente según su objeto: en primer lugar, las normas que prohíben o restringen el uso de armas y, en segundo lugar, las normas que protegen los bienes de carácter civil. ${ }^{34}$

\subsection{Derecho internacional humanitario consuetudinario}

El CICR ha adelantado estudios para establecer cuáles normas forman parte de este corpus iuris. La costumbre internacional ha sido reconocida por el artículo 38 del Estatuto de la CIJ como una de las fuentes de derecho internacional. Killian la define como: "La existencia de una práctica reiterada y con carácter uniforme, llevada a cabo por sujetos del derecho internacional público, con la convicción de que se está realizando en el marco de cumplimiento de una norma jurídica". ${ }^{35}$ Se ha indicado tradicionalmente que la costumbre internacional exige dos factores que la regla cumple para ser considerada como tal: una práctica estatal extendida y manifestaciones de la convicción de que la práctica es requerida por el derecho internacional. ${ }^{36}$

En el primer volumen del trabajo adelantado por Henckaerts y Doswald-Beck; el CICR reconoce las reglas del DIH consuetudinario número 43 a 45 como normas relativas al ambiente natural. Cabe resaltar la regla 45, que dispone:

34 Bárbara Díaz Santis, "La ambientalización del derecho internacional humanitario" (Tesis de doctorado, Universitat Pompeu Fabra, 2016), 52-174.

35 Kevin Killian, "La costumbre en el derecho internacional (precedentes judiciales del derecho interno como medios de prueba)", Lecciones y Ensayos, núm. 93 (2014): 187, https://revistas-colaboracion.juridicas.unam. mx/index.php/lecciones-ensayos/article/download/13941/12438 (acceso octubre 12, 2021).

36 Michael Scharf, "Accelerated Formation of Customary International Law", ILSA Journal of International E Comparative Law 20, núm. 2 (2014): 305, https://nsuworks.nova.edu/ilsajournal/vol20/iss2/5/ (acceso octubre 12, 2021). 
Queda prohibido el empleo de métodos o medios de guerra concebidos para causar, o de los cuales quepa prever que causen, daños extensos, duraderos y graves al medio ambiente natural. La destrucción del medio ambiente natural no puede usarse como arma. ${ }^{37}$

\subsubsection{Principios del derecho internacional humanitario}

En tercer lugar, es necesario identificar los principios reconocidos por este régimen, que guían la conducta de los sujetos que cometen las hostilidades. En términos generales, se han reconocido los principios de distinción, humanidad, proporcionalidad y necesidad militar.

El principio de distinción establece:

[... solamente los que participan en las hostilidades (ante la inexistencia, en el marco de los conflictos internos, del estatuto jurídico de combatiente) y los objetivos militares podrán ser objeto de ataques, no pudiendo, por ende, atacarse a la población civil, que en todo tiempo y circunstancia deberá ser respetada. ${ }^{38}$

Muy ligado al principio de distinción, el principio de humanidad exige respetar a combatientes y no combatientes con dignidad, de modo que no se les hará padecer sufrimientos innecesarios. ${ }^{39}$

El principio de proporcionalidad alude a la exigencia de que los efectos de los métodos de guerra utilizados no sean desproporcionados respecto a la ventaja militar que se busca obtener, ${ }^{40}$ en particular, que los daños colaterales que puedan aparecer a la hora de efectuar una actividad bélica no sean muy gravosos para quien los recibe frente a la ventaja militar que resulte de atacar al objetivo militar correspondiente.

37 Jean-Marie Henckaerts y Louise Doswald-Beck, El derecho internacional humanitario consuetudinario, Volumen 1: Normas (Buenos Aires: Comité Internacional de la Cruz Roja, 2007), 168.

38 Elizabeth Salmón, Introducción al derecho internacional humanitario (Lima: Comité Internacional de la Cruz Roja, 2004), 54.

39 Salmón, Introducción, 54.

40 Salmón, Introducción, 56 
El principio de necesidad militar:

[...] que justifica aquellas medidas de violencia militar que son necesarias y proporcionadas para garantizar el rápido sometimiento del enemigo con el menor costo posible en vidas humanas y recursos económicos. Es decir que en el transcurso de las operaciones militares solo se deben tomar las medidas necesarias para obtener el objetivo propuesto. ${ }^{41}$

\subsubsection{Suficiencia del derecho internacional humanitario en la protección del ambiente}

En términos generales, se ha entendido que este régimen es insuficiente para la protección eficaz del ambiente. En particular, Craig afirma que el DIH presenta una ambigüedad en la consagración del umbral que se debe superar para establecer que una acción bélica vulnera este régimen. El umbral de "daños extensos, duraderos y graves" recurrente en los tratados de DIH y en el derecho consuetudinario es un término que acepta diversas interpretaciones: con "extensos", las partes del conflicto no tienen claridad acerca de la dimensión (metros o kilómetros a la redonda y cuántos); con "duraderos", no existe certeza si es frente al ataque mismo o a sus efectos y cuál es la medida de tiempo idónea (meses, años o décadas) y con "severo", se generan dudas frente al grado de intensidad, en especial ante la consideración de los principios de necesidad militar y proporcionalidad propios del $\mathrm{DIH} .{ }^{42}$

El segundo problema que resalta este autor es la definición de la intención y el daño colateral; pues existe poca claridad respecto a la vulneración a las normas del DIH para la protección del ambiente cuando el objetivo militar no es el propio ambiente, pero se produce un daño no esperado o colateral. En este caso no sería posible evaluar si ocurrió una vulneración al DIH. ${ }^{43}$

Desde otra perspectiva, se ha propuesto la creación de un principio de ambituidad, que considera la destrucción del ambiente como una acción que vulnera el DIH a manera de principio general de este régimen. Koppe sostiene que esta es la única forma de entender que existan disposiciones como los artículos 35 y 55 del Protocolo

\footnotetext{
41 Salmón, Introducción, 56.

42 Jeffrey Craig, "The Protection of the Environment under International Humanitarian Law", https://www. researchgate.net/publication/332035942_The_protection_of_the_Environment_under_International_Humanitarian_Law (acceso diciembre 20, 2020).

43 Craig, "The Protection".
} 
Adicional I a las Convenciones de Ginebra. ${ }^{44}$ Si bien no se profundizará en este asunto, la argumentación de Koppe, incluso si no se acepta que es lo suficientemente fuerte para consagrar un principio general del DIH, sí apoya la idea de que existe una conciencia pública que exige la protección ambiental.

Otras posturas han afirmado que, ante el fallo del DIH de aplicar un enfoque preventivo en la protección del ambiente, es necesario definir medidas de reparación ex post que ayuden a compensar el daño causado. ${ }^{45}$ A pesar de lo anterior, cabe resaltar que, si no se considera que una acción es contraria a derecho, dichas medidas no serán aplicables; en consecuencia, cae esta posición en la misma discusión: ¿fue la acción contraria a derecho?

Droege y Tougas ${ }^{46}$ sugieren que, ante la insuficiencia de los instrumentos legales del $\mathrm{DIH}$, es necesario que la comunidad internacional adelante dos acciones: en primer lugar, clarificar la ley para que la protección de objetos civiles pueda extenderse al ambiente, se protejan algunas áreas de mayor importancia ecológica y se concreten mecanismos que aborden las consecuencias ambientales de las hostilidades. En segundo lugar, analizar a profundidad de la aplicación del DIA como referente para la protección del ambiente durante los conflictos armados.

Hasta el momento, la respuesta de las instancias judiciales ha sido mínima frente a posibles vulneraciones al ambiente en los conflictos armados. Se han encontrado breves referencias al daño ambiental en sentencias de la $\mathrm{CIJ}$, mas no un pronunciamiento en el marco de un conflicto. El único desarrollo claro que se ha brindado en este sentido ha sido en un escenario cuasi-judicial: la Comisión de Compensación de las Naciones Unidas para el conflicto del Golfo.

Desde la CPI se viene trabajando para considerar los ataques al ambiente como una razón para dar prioridad a los casos que adelanta esta instancia judicial. Lo anterior se ve claramente desarrollado en el Policy Paper emitido por la fiscal de la CPI en 2016, cuyo párrafo 41 dispone que esa oficina daría prioridad a procesar los crímenes del Estatuto de Roma que son cometidos por medio o como resultado

44 Koppe, "The Principle", 65-68.

45 Meredith DuBarry Huston, "Wartime Environmental Damages: Financing the Cleanup", University of Pennsylvania Journal of International Law 23, núm. 4 (2002): 909, https://scholarship.law.upenn.edu/cgi/ viewcontent.cgi?article $=1289 \&$ context=jil (acceso octubre 12, 2021).

46 Cordula Droege y Marie-Lousie Tougas, "The Protection of the Natural Environment in Armed Conflict-Existing Rules and Need for Further Legal Protection", Nordic Journal of International Law 82, núm. 1 (2013): 51-52, DOI: https://doi.org/10.1163/15718107-08201003 (acceso octubre 12, 2021). 
de la destrucción del ambiente, la explotación ilegal de recursos naturales o el despojo ilegal de tierras. ${ }^{47}$

A pesar de lo anterior, existen serias dificultades para su empleo. La primera barrera es el alcance de la CPI, ya que solo tiene jurisdicción sobre personas de los 123 Estados parte. Por fuera de este alcance se encuentran personas pertenecientes a países como Estados Unidos, China e India, ${ }^{48}$ por lo que muchas situaciones de conflicto quedarían por fuera.

De igual forma, la adecuación a alguno de los crímenes reconocidos en el Estatuto de Roma es una barrera para esta postura. En términos generales, se ha reconocido que la CPI enjuicia crímenes de guerra, genocidio y crímenes de lesa humanidad; por la naturaleza de los ataques contra el ambiente es en esta última categoría en la que se encuadraría de mejor manera, sin que esto sea definitivo, ${ }^{49}$ puesto que se requiere que dicho ataque se extienda en el territorio y sea sistemático, en virtud de la definición del Estatuto de Roma. Así, se cae en el mismo problema que tiene el DIH convencional: se limita el ámbito de aplicación del crimen, lo que deja diversas acciones por fuera de su conocimiento. ${ }^{50}$

Se ha propuesto hacer una enmienda al Estatuto de Roma, tendiente a incluir un nuevo crimen justiciable por la CPI: el ecocidio. En la asamblea de los Estados parte de la CPI número 18, realizada en diciembre de 2019, se formuló un llamado para que se extendiera la jurisdicción de la CPI a este crimen, pero la propuesta no fue aprobada. Ricardo Pereira ${ }^{51}$ ha destacado que la insuficiencia del enfoque del Estatuto de Roma frente a la posibilidad de enjuiciar las acciones que atentan contra el ambiente requiere la adopción del ecocidio como crimen. En este sentido, la necesidad de incorporar una enmienda prueba la insuficiencia de este instrumento.

47 Corte Penal Internacional, "Policy Paper on Case Selection and Prioritisation", https://www.icc-cpi.int/ itemsdocuments/20160915_otp-policy_case-selection_eng.pdf (acceso octubre 12, 2021).

48 Hogan Lovells, "Can Environmental Damage be Prosecuted as a Crime under International Law?", https:// www.lexology.com/library/detail.aspx?g=169810a5-727a-4c9e-8f4c-5c894bf6ee29 (acceso diciembre 20, 2020).

49 Jessica Durney, "Crafting a Standard: Environmental Crimes as Crimes Against Humanity under the International Criminal Court", Hastings Environmental Law Journal 24, núm. 2 (2018): 429, https://repository. uchastings.edu/cgi/viewcontent.cgi?article=1428\&context=hastings_environmental_law_journal (acceso octubre 12, 2021).

50 Ricardo Pereira, "After the ICC Office of the Prosecutor's 2016 Policy Paper on Case Selection and Prioritisation: Towards an International Crime of Ecocide?", Criminal Law Forum 31 (2020): 211, https://papers.ssrn.com/ sol3/papers.cfm?abstract_id=3654359 (acceso octubre 12, 2021).

51 Pereira, "After the ICC", 211. 
Entonces, se puede concluir que sería posible la aplicación de la cláusula Martens, con el fin de brindar pautas a las partes del conflicto en la protección del ambiente durante su ocurrencia, ya que existe una insuficiencia general en el DIH para regularla.

\section{Uso de la cláusula Martens y normas de DIA}

Tras la revisión hecha hasta este momento, es posible advertir que el DIH carece de normas idóneas que garanticen la protección del ambiente durante los conflictos armados, porque son demasiado amplias o ambiguas.

Es preciso revisar las formas en que los estándares del DIA pueden ser empleados a la manera en que los Estados y actores del conflicto conducen las hostilidades; en otras palabras, cómo superar la fragmentación del derecho internacional y evitar el inicio de un proceso de negociación y adopción de un convenio internacional.

Las exigencias de la conciencia pública son las herramientas ideales para lograr este cometido. Como se mencionó, la deliberación pública, basada en las teorías de la democracia deliberativa, es una forma de conocer estas exigencias. En el escenario del DIA, las conferencias y sus declaraciones se convierten en el ejemplo perfecto de ello.

La Declaración de Estocolmo de 1972, la Declaración de Río de 1992, Río +20 y las recomendaciones del Congreso Mundial de la Naturaleza son instrumentos considerados como soft law, pero incluyen amplias directrices en materia ambiental que ayudan a dirigir el comportamiento de los Estados y las personas. Al haber sido adoptados en una discusión multilateral con amplias visiones, los principios consagrados en estos instrumentos son exigencias de la conciencia pública. Los principios de precaución, de prevención de la contaminación y de "quien contamina paga", entre otros, son guías para la conducción de hostilidades en los conflictos armados.

El principio de prevención ha sido entendido desde dos perspectivas. De manera tradicional, hace referencia a la obligación de los Estados de evitar el daño ambiental transfronterizo; a pesar de ello, Max Valverde Soto ${ }^{52}$ amplía la necesidad de que los Estados se obliguen a prevenirlo también en sus propios territorios.

52 Max Valverde Soto, "General Principles of International Environmental Law", ILSA Journal of International E Comparative Law 3, núm. 1(1996): 199-200, https://nsuworks.nova.edu/ilsajournal/vol3/iss1/10/ (acceso octubre 12, 2021). 
El principio de prevención busca que los Estados ejecuten las acciones necesarias en una etapa temprana de cualquier actividad para precaver tal daño y adopten una actitud activa en el control o la mitigación de este. Dicho principio debería irradiar las acciones militares, en el sentido de priorizar las acciones que causen un menor impacto al ambiente: ante dos posibles acciones, el operador deberá preferir aquella que cause un menor impacto ambiental.

El principio de precaución es aquel por el cual, ante la duda científica de los efectos adversos que una actividad conlleva en el ambiente, los Estados deben adoptar medidas para evitar al máximo la consumación de este o cualquier otro daño. En un escenario bélico, los Estados deberán conocer los impactos que sus métodos de guerra ocasionan y, si hay ausencia de certeza científica respecto a un riesgo que estos representen para el ambiente, deberían abstenerse de ejecutar dicha acción. El mejor ejemplo de ello es usar agentes biológicos, de cuyo efecto se desconoce el alcance o la forma de controlarlo.

En cuanto a daños ya causados, el derecho ambiental internacional ha instituido el principio de "quien contamina paga" o contaminador pagador, por el cual existe una responsabilidad de compensar o remediar el daño ambiental provocado, bien sea lícito o ilícito. Así, el Estado que adelante la acción bélica deberá compensar los daños ambientales que genere, inclusive si su acción, a la luz del DIH, es legítima. En este punto cabe destacar que la naturaleza de este principio no es sancionatoria, sino compensatoria y los Estados quedarían sujetos a apoyar en la remediación del daño ambiental que la acción bélica pueda ocasionar.

Con referencia a la planeación del ataque, sin duda alguna, los principios de prevención y de precaución incorporados en las Declaraciones de Estocolmo y de Río conminan a los Estados a considerar no solo las cuestiones propias del DIH, como cumplir con la necesidad y proporcionalidad, sino el posible efecto que su ataque tendría en el ambiente. A manera de ejemplo, si tiene cinco posibles locaciones de ataque, pero dos de ellas tienen mayor cercanía a una fuente hídrica, estas dos deben ser evitadas, ya que se conoce que un factor de expansión y, por lo tanto, de mayor contaminación del hidrocarburo derramado es la presencia de fuentes hídricas que lo diseminan (principio de prevención). Si a pesar de haber considerado estos riesgos el Estado adelanta el ataque y provoca un daño ambiental directamente asociado a su acción, tendrá la responsabilidad de compensarlo o remediarlo. Con esto en mente se salvaguarda el ambiente, al lograr que, incluso tras ocasionar un daño, sus consecuencias no queden desatendidas al finalizar el conflicto. 


\section{Conclusiones}

Ante la falta de normas adecuadas en el DIH, la Cláusula Martens es una herramienta para permite salvaguardar el ambiente en los conflictos armados. Luego de analizar el contenido de la cláusula, en especial de las exigencias de la conciencia pública como fuente de derecho internacional humanitario, se argumentó que el derecho blando o soft law ambiental se podía entender también como fuente.

Las exigencias de la conciencia pública deben considerarse en un sentido amplio: en primer lugar, pueden ser creadas no solo por Estados, lo que se aleja de la visión más tradicional de los generadores del derecho internacional. En segundo lugar, son manifestaciones adoptadas en foros con sujetos que llegan a puntos comunes entre visiones variadas, de forma que se expresa la manera en que piensa el mundo en general.

Los estándares del derecho ambiental internacional incluidos en instrumentos no vinculantes como la Declaración de Río y la Declaración de Estocolmo son exigencias de la conciencia pública por las cuales los Estados y los actores del conflicto deben moldear sus acciones bélicas. Con estas reglas es exigible el cumplimiento de los principios de prevención, precaución y contaminador-pagador.

No es necesario adoptar un tratado para que se proteja el ambiente mientras exista una situación de conflicto de carácter internacional o no internacional, pues hoy en día se cuenta con la cláusula Martens, como herramienta que permite a los Estados definir reglas de conducta y obligaciones mientras adelantan hostilidades. Estos principios también exigen medidas ex post por parte de los Estados, de modo que, aun cuando han decidido llevar a cabo la acción bélica, compensen los daños causados.

\section{Referencias}

Ahmed, Arif y Jahid Mustofa. "Role of Soft Law in Environmental Protection: An Overview". Global Journal of Politics and Law Research 4, núm. 2 (marzo 2016): 1-18, https://www. eajournals.org/wp-content/uploads/Role-of-Soft-Law-in-Environmental-ProtectionAn-Overview.pdf (acceso octubre 12, 2021).

Cárdenas Castañeda, Fabián Augusto. "A Call for Rethinking the Sources of International Law: Soft Law and the Other Side of the Coin". Anuario mexicano de derecho internacional 13 (2013): 355-403, http://www.scielo.org.mx/scielo. 
php?script=sci_abstract\&pid=\$1870-46542013000100008\&lng=es\&nrm=iso\&th $\mathrm{g}=$ en (acceso octubre 12, 2021).

Comité Internacional de la Cruz Roja [CICR]. "Listado de tratados del derecho internacional humanitario". https://ihl-databases.icrc.org/applic/ihl/ihl.nsf/vwTreatiesByDate.xsp (acceso octubre 5, 2020).

Comité Internacional de la Cruz Roja [CICR]. Convención relativa a las leyes y costumbres de la guerra terrestre. La Haya, 18 de octubre de 1907.

Corte Penal Internacional. "Policy Paper on Case Selection and Prioritisation". https://www. icc-cpi.int/itemsdocuments/20160915_otp-policy_case-selection_eng.pdf (acceso octubre 12, 2021).

Craig, Jeffrey. "The Protection of the Environment under International Humanitarian Law". https://www.researchgate.net/publication/332035942_The_protection_of_the_Environment_under_International_Humanitarian_Law (acceso diciembre 20, 2020).

De Oliveira Mazzuoli, Valerio. Derecho internacional público contemporáneo. Barcelona: Bosch, 2019.

Díaz Santis, Bárbara. "La ambientalización del derecho internacional humanitario". Tesis de doctorado, Universitat Pompeu Fabra, 2016.

Droege, Cordula y Marie-Lousie Tougas. "The Protection of the Natural Environment in Armed Conflict-Existing Rules and Need for Further Legal Protection". Nordic Journal of International Law 82, núm. 1 (2013): 21-52, DOI: https://doi.org/10.1163/1571810708201003 (acceso octubre 12, 2021).

DuBarry Huston, Meredith. "Wartime Environmental Damages: Financing the Cleanup". University of Pennsylvania Journal of International Law 23, núm. 4 (2002): 899-929, https://scholarship.law.upenn.edu/cgi/viewcontent.cgi?article $=1289 \&$ context=jil (acceso octubre 12, 2021).

Durant, Sarah y José Carlos Brito. "Stop Military Conflicts from Trashing Environment". Nature 571, núm. 7766 (2019).

Durney, Jessica. "Crafting a Standard: Environmental Crimes as Crimes Against Humanity Under the International Criminal Court". Hastings Environmental Law Journal 24, núm. 2 (2018): 413-430, https://repository.uchastings.edu/cgi/viewcontent.cgi?arti cle $=1428 \&$ context=hastings_environmental_law_journal (acceso octubre 12, 2021).

Ferrari Puerta, Alberto José. "El concepto de guerra justa a través de los tiempos". Novum Jus 15 núm. 1 (enero-junio, 2021): 91-115, https://novumjus.ucatolica.edu.co/article/ view/3485 (acceso octubre 12, 2021).

Gasser, Hans-Peter. "For Better Protection of the Natural Environment in Armed Conflict: A Proposal for Action". American Journal of International Law 89, núm. 3 (1995): 637-644, DOI:10.2307/2204184 (acceso octubre 12, 2021). 
Henckaert, Jean-Marie y Louise Doswald-Beck. El derecho internacional humanitario consuetudinario. Volumen 1: Normas. Buenos Aires: Comité Internacional de la Cruz Roja, 2007.

Islam, Jahidul. "The Protection of Environment during Armed Conflict: A Review of IHL". Society \& Change 11, núm. 3 (julio-septiembre, 2017): 49-64, https://societyandchange. com/uploads/1531545952.pdf (acceso octubre 12, 2021).

Killian, Kevin. "La costumbre en el derecho internacional (precedentes judiciales del derecho interno como medios de prueba)". Lecciones y Ensayos, núm. 93 (2014): 183-206, https://revistas-colaboracion.juridicas.unam.mx/index.php/lecciones-ensayos/article/ download/13941/12438 (acceso octubre 12, 2021).

Koppe, Erik. "The Principle of Ambituity and the Prohibition against Excessive Collateral Damage to the Environment during Armed Conflict". Nordic Journal of International Law 82, núm. 1 (2013): 53-82, DOI: https://doi.org/10.1163/15718107-08201004 (acceso octubre 12, 2021).

Lovells, Hogan. "Can Environmental Damage be Prosecuted as a Crime under International Law?". https://www.lexology.com/library/detail.aspx?g=169810a5-727a-4c9e-8f4c5c894bf6ee29 (acceso diciembre 20, 2020).

Monroy-Cabra, Marco Gerardo. "Aproximación al concepto de fuentes del derecho internacional”. Estudios Socio-Jurídicos 7, núm. 2 (2005): 77-91, https://revistas. urosario.edu.co/index.php/sociojuridicos/article/view/166 (acceso octubre 12, 2021).

Organización de las Naciones Unidas [ONU], Comisión de Derecho Internacional. "Capítulo VI. Protección del medio ambiente en relación con los conflictos armados, Doc. A/74/10”. https://legal.un.org/ilc/reports/2019/spanish/chp6.pdf (acceso octubre 12, 2021).

Organización de las Naciones Unidas [ONU], Comisión de Derecho Internacional. "Segundo informe sobre la protección del medio ambiente en relación con los conflictos armados presentado por Marja Lehto, relatora especial, Doc. A/CN.4/728". https://digitallibrary. un.org/record/3801185/files/A_CN-4_728-ES.pdf (acceso octubre 12, 2021).

Organización de las Naciones Unidas [ONU], Corte Internacional de Justicia. Opinión consultiva de la Corte Internacional de Justicia sobre la legalidad de la amenaza o el empleo de armas nucleares. Nueva York, 8 de julio de 1996.

Pereira, Ricardo. "After the ICC Office of the Prosecutor's 2016 Policy Paper on Case Selection and Prioritisation: Towards an International Crime of Ecocide?". Criminal Law Forum 31 (2020): 179-224, https://papers.ssrn.com/sol3/papers.cfm?abstract_id=3654359 (acceso octubre 12, 2021).

Pustogarov, Vladimir. "The Martens Clause in International Law". Journal of the History of International Law 1, núm. 2 (enero 1999): 125-135, DOI: https://doi. org/10.1163/15718059920956715 (acceso octubre 12, 2021). 
Saco, Víctor. "Resolución de conflictos normativos en derecho internacional público". Agenda Internacional 15, núm. 26 (2008): 231-261, https://revistas.pucp.edu.pe/index.php/ agendainternacional/article/view/3689 (acceso octubre 12, 2021).

Salmón, Elizabeth. Introducción al derecho internacional humanitario. Lima: Comité Internacional de la Cruz Roja, 2004.

Sandoz, Yves. "El Comité Internacional de la Cruz Roja: guardián del derecho internacional humanitario". https://www.icrc.org/es/doc/resources/documents/misc/about-theicrc-311298.htm (acceso octubre 5, 2020).

Scharf, Michael. "Accelerated Formation of Customary International Law". ILSA Journal of International \& Comparative Law 20, núm. 2 (2014): 305-341, https://nsuworks. nova.edu/ilsajournal/vol20/iss2/5/ (acceso octubre 12, 2021).

Schmitt, Michael. "Humanitarian Law and the Environment". Denver Journal of International Law and Policy 28, núm. 3 (1999): 265-323, https://digitalcommons.du.edu/cgi/ viewcontent. cgi? article $=1518 \&$ context=djilp (acceso octubre 12, 2021).

Sparrow, Rob. "Ethics as a Source of Law: The Martens Clause and Autonomous Weapons". https://blogs.icrc.org/law-and-policy/2017/11/14/ethics-source-law-martens-clauseautonomous-weapons/ (acceso octubre 12, 2021).

Unión Internacional para la Conservación de la Naturaleza [UICN]. "Miembros de la UICN". https://www.iucn.org/es/miembros-de-la-uicn (acceso julio 13, 2021).

Valverde Soto, Max. "General Principles of International Environmental Law". ILSA Journal of International \& Comparative Law 3, núm. 1(1996): 193-209, https://nsuworks.nova. edu/ilsajournal/vol3/iss1/10/ (acceso octubre 12, 2021).

Vöneky, Silja. "A New Shield for the Environment: Peacetime Treaties as Legal Restraints of Wartime Damage". Reciel 9, núm. 1 (2000): 20-33, https://www.readcube.com/ articles/10.1111\%2F1467-9388.00229 (acceso octubre 12, 2021). 